\title{
Biofilm differentiation and dispersal in mucoid Pseudomonas aeruginosa isolates from patients with cystic fibrosis
}

\author{
Correspondence \\ Sylvia M. Kirov \\ S.M.Kirov@utas.edu.au
}

Received 16 April 2007

Revised 26 June 2007

Accepted 4 July 2007

\author{
Sylvia M. Kirov, ${ }^{1}$ Jeremy S. Webb, ${ }^{2}+$ Che Y. O'May, ${ }^{1}$ David W. Reid, ${ }^{1}$ \\ Jerry K. K. Woo, ${ }^{2}$ Scott A. Rice ${ }^{2}$ and Staffan Kjelleberg ${ }^{2}$
${ }^{1}$ School of Medicine, University of Tasmania Clinical School, 43 Collins St, Hobart, Tasmania 7001, Australia Bio-innovation, University of New South Wales, Sydney, NSW 2052, Australia \\ ${ }^{2}$ School of Biotechnology and Biomolecular Sciences and Centre for Marine Biofouling and
}

\begin{abstract}
Intractable biofilm infections with Pseudomonas aeruginosa are the major cause of premature death associated with cystic fibrosis (CF). Few studies have explored the biofilm developmental cycle of $P$. aeruginosa isolates from chronically infected individuals. This study shows that such clinical isolates exhibit biofilm differentiation and dispersal processes similar to those of the better-studied laboratory $P$. aeruginosa strain PAO1 in the glass flow-cell (continuous-culture) biofilm model, albeit they are initially less adherent and their microcolonies are slower to develop and show heterogeneous, strain-specific variations in architecture. Confocal scanning laser microscopy combined with LIVE/DEAD viability staining revealed that in all CF biofilms bacterial cell death occurred in maturing biofilms, extending from the substratum to the central regions of mature microcolonies to varying degrees, depending on the strain. Bacteriophage activity was detected in the maturing biofilms of all CF strains examined and the amount of phage produced paralleled the degree of cell death seen in the biofilm. Some CF strains exhibited 'seeding dispersal' associated with the above phenomena, producing 'hollowing' as motile cells evacuated from the microcolony interiors as has been described for strain PAO1. Moreover, morphotypic cell variants were seen in the biofilm effluents of all CF strains. For those CF strains where marked cell death and seeding dispersal occurred in the microcolonies, variants were more diverse (up to five morphotypes) compared to those of strain PAO1 (two morphotypes). Given that variants of strain PAO1 have enhanced colonization traits, it seems likely that the similar biofilm dispersal events described here for CF strains contribute to the variability seen in clinical isolates and the overall persistence of the $P$. aeruginosa in the CF airway.
\end{abstract}

\section{INTRODUCTION}

Cystic fibrosis (CF), the most common inherited lethal genetic disease in Caucasian populations, results from mutations in the CF transmembrane conductance regulator (CFTR) gene. These mutations result in defective cyclic-AMP-regulated chloride channel activity that impairs pancreatic, pulmonary and intestinal functions (Wilschanski et al., 1995). In the lung, mucus secretions become depleted of paraciliary fluid in the lower respiratory tract, impairing the clearance of inhaled

tPresent address: School of Biological Sciences, University of Southampton, Southampton SO17 1BJ, UK.

Abbreviations: AHLs, $\mathrm{N}$-acylhomoserine lactones; $\mathrm{CF}$, cystic fibrosis; HAQs, 4-hydroxy-2-alkylquinolines; HHO, 4-hydroxy-2-heptylquiniline; HSL, homoserine lactone; LCV, large-colony variant; PQS, Pseudomonas quinolone signal; $\mathrm{OS}$, quorum sensing; SCV, small-colony variant. microbes, resulting in chronic infections and an exaggerated inflammatory response that leads to progressive deterioration in lung function and ultimately premature death (Lyczak et al., 2002; Saiman \& Siegel, 2004). The opportunistic bacterial pathogen Pseudomonas aeruginosa is the most important agent involved in chronic lung infection in CF patients (Burns et al., 2001; Lyczak et al., 2002). The CF lung environment favours conversion of this organism from a motile, planktonic form to a mucoid, sessile biofilm mode of growth (Costerton et al., 1999; O’May et al., 2006; Worlitzsch et al., 2002). Recognized stages in biofilm development elucidated in experimental model systems include initial attachment, the formation of multicellular structures ('microcolonies'), and the maturation of microcolonies into thick, three-dimensional structures encased in an exopolymeric matrix and interspersed with water channels (Stoodley et al., 2002). In the 
CF lung mucus, large aggregates of mucoid $P$. aeruginosa biofilm communities (growing as per the later stages described in biofilm model systems) have been described (Worlitzsch et al., 2002). In this form the organism becomes impossible to eradicate with existing therapies and is refractory to host defences (Costerton et al., 1999; Hassett et al., 2002).

Although the antibiotic resistance of such infections is well documented, the reasons for it are not fully understood. The mechanisms proposed all reflect the multicellular nature of the biofilm communities. They include the delayed penetration of the agent into the biofilm (exopolymer blocks diffusion or even actively binds agents), the slower growth rate of at least some biofilm bacteria (antibiotics target activities such as cell division and nutrient uptake in growing bacterial cells), and the altered microenvironments (such as anaerobiosis and acidic waste products in the biofilm interior that might directly antagonize the action of an antibiotic or cause physiological changes in the bacteria that lower antibiotic uptakes) (Stewart \& Costerton, 2001). Antibiotic-resistant 'persister' cell phenotypes that forfeit rapid propagation to ensure population survival in the presence of lethal factors can also be generated in biofilms (Lewis, 2005). More recently, intensive biofilm research of a number of model organisms, including the laboratory strain $P$. aeruginosa $\mathrm{PAO}$, in in vitro biofilm models has identified a common biofilm developmental cycle or series of adaptive responses involving an active dispersal mechanism, termed 'seeding dispersal', that itself is associated with the generation of genetic diversity in biofilm communities, increasing the chances of survival of the organism (Boles et al., 2004; Hentzer et al., 2005; Koh et al., 2007; Mai-Prochnow et al., 2004; Purevdorj-Gage et al., 2005; Webb et al., 2003).

Seeding dispersal is characterized by 'hollowing' in mature microcolonies caused by highly motile cells departing the microcolony interior, leaving behind a stationary cluster of 'wall' cells. Hollowing is associated with cell death in a subpopulation of the interior cells. For P. aeruginosa PAO1, these cell death and dispersal events have been linked to the conversion of a prophage to a superinfective lytic form observed at the same time and location as the accumulation of reactive oxygen and nitrogen species (RONS) (Barraud et al., 2006; Webb et al., 2003). Significantly, cells of $P$. aeruginosa $\mathrm{PAO} 1$ released by seeding dispersal exhibit phenotypic and functional diversification. Thus, some biofilm-derived variants show an increased ability to disseminate, whereas others manifest accelerated biofilm formation (Kirisits et al., 2005; Webb et al., 2004). Antibiotic resistance has also been linked to phenotypic variation and biofilms (Drenkard \& Ausubel, 2002).

Clearly it is important that more is learnt of the dispersal mechanism and its relevance to clinical isolates if improved methods to deal with chronic $P$. aeruginosa biofilm infections in CF are to be found. Although seeding dispersal has been well documented in the laboratory strain PAO1
(Purevdorj-Gage et al., 2005), there have been few published studies of the biofilm biology of CF clinical $P$. aeruginosa strains. Lee et al. (2005) examined a selection of non-mucoid $\mathrm{CF}$ isolates and demonstrated that such strains had highly variable biofilm architecture consistent with our and many other published observations that $P$. aeruginosa isolates with different properties (e.g. decreased motilities and virulence factor expression, increased antibiotic resistance) evolve within the CF respiratory tract (Head \& Yu, 2004; Mahenthiralingam et al., 1994; O’May et al., 2006; Oliver et al., 2000). Lee et al. (2005) did not examine mucoid isolates or dispersal in their CF strain biofilms. A mucoid CF strain examined by Purevdorj-Gage et al. (2005) was, however, found to be 'seeding dispersal negative', leading to speculation that this mechanism may in fact not be relevant in the clinical setting (PurevdorjGage et al., 2005). Here, we expand on our previously published comment on this finding (Kirov et al., 2005) and document experiments that show that seeding dispersal does occur in CF strain biofilms. Moreover, we present evidence that such dispersal events may well be important in the overall persistence of $P$. aeruginosa in the CF lung by facilitating the release of multiple dispersal cell variants.

\section{METHODS}

Bacterial strains and culture media. $P$. aeruginosa strain PAO1 was originally isolated from a burn wound (Holloway, 1955). The Tasmanian clinical strains of $P$. aeruginosa (strains $3 \mathrm{~A}, 18 \mathrm{~A}, 32 \mathrm{~A}$ and $75 \mathrm{~A}$ ) included in this study were isolated from CF sputum samples of chronically infected individuals, as previously described (O'May et al., 2006). The Australian mainland 'clonal' CF isolate (strain MC1A) was obtained from the Royal Children's Hospital Melbourne, Australia (Armstrong et al., 2002). These strains were all genotypically distinct by PFGE with restriction enzyme SpeI and random amplified polymorphic DNA (RAPD) assay (Mahenthiralingam et al., 1996). The CF isolates were mucoid on initial isolation and had functional properties (decreased motilities and adherence, impaired biofilm formation in in vitro models especially under anaerobic conditions) typical of Pseudomonas 'biofilm phenotypes' isolated from chronically infected individuals (O'May et al., 2006). The strains were further characterized for virulence determinants (LasA protease, LasB elastase and pyocyanin) using methods described elsewhere (Diggle et al., 2002). They were also examined for quorum-sensing (QS) signalling molecules [ $N$-acylhomoserine lactones (AHLs) and 4-hydroxy-2alkylquinolines (HAQs)]. In brief, these were identified following extraction from overnight $\mathrm{LB}_{10}$ broth cultures, thin-layer chromatography and detection with $\operatorname{lu} x C D A B E$ reporter strains prepared at the Centre for Biomolecular Sciences, University of Nottingham, UK (Diggle et al., 2003; Middleton et al., 2002). Strains were stored at $-80{ }^{\circ} \mathrm{C}$ in $30 \%(\mathrm{v} / \mathrm{v})$ glycerol and subcultured from storage onto Luria-Bertani $\left(\mathrm{LB}_{10}\right)$ medium [tryptone $10 \mathrm{~g} \mathrm{l}^{-1}, \mathrm{NaCl} 10 \mathrm{~g} \mathrm{l}^{-1}$, yeast extract $5 \mathrm{~g} \mathrm{l}^{-1}$ and $15 \mathrm{~g} \mathrm{l}^{-1}$ agar], for the experiments below. Bacterial inocula for the biofilm experiments were grown in $\mathrm{LB}_{10}$ broth $(\sim 16 \mathrm{~h}$, $37{ }^{\circ} \mathrm{C}$, with shaking) and standardized $\left(\mathrm{OD}_{610}\right)$ so that an inoculum of $0.5 \mathrm{ml}$ contained $\sim 10^{9}$ bacteria $\mathrm{ml}^{-1}$. Biofilms (continuous-culture flow-cell experiments) were cultivated in $\mathrm{M9}$ minimal medium containing $48 \mathrm{mM} \mathrm{Na}_{2} \mathrm{HPO}_{4}, 22 \mathrm{mM} \mathrm{KH}_{2} \mathrm{PO}_{4}, 9 \mathrm{mM} \mathrm{NaCl}, 19 \mathrm{mM}$ $\mathrm{NH}_{4} \mathrm{Cl}, 2 \mathrm{mM} \mathrm{MgSO}{ }_{4}, 100 \mu \mathrm{M} \mathrm{CaCl}_{2}$ and $5 \mathrm{mM}$ glucose.

Biofilm flow-cell (continuous-culture) system. Biofilms were grown at room temperature in three-channel flow cells with 
individual channel dimensions of $0.3 \times 4 \times 40 \mathrm{~mm}$, as described elsewhere (Moller et al., 1998; Webb et al., 2003). Following inoculation with bacteria prepared as described above, the channels were inverted for $2 \mathrm{~h}$ with no flow, to allow bacterial adherence. This time was extended beyond the standard $1 \mathrm{~h}$ because of decreased adherence abilities of CF strains to glass compared to strain PAO1 (O'May et al., 2006). Media flow (mean velocity of $0.2 \mathrm{~mm} \mathrm{~s}^{-1}$ ) was then started and biofilm development followed for up to 8 days, as described below. Three sets of flow cells were run in parallel in each experiment, and duplicate or triplicate channels of each strain were examined in at least two experiments.

Microscopy. Adhesion and microcolony development of all strains were initially followed daily by bright-field microscopy (Leica DMLB Epifluorescent microscope) and representative fields (minimum five per chamber) were recorded by photography. In brief, individual flow cells were sealed by clamping the in-flow and out-flow tubing to each channel of the flow cell. The flow of M9 medium was then temporarily stopped and individual flow channels were examined directly on the microscope stage. Microcolonies and mature biofilms (days 6-7) were subsequently stained using the BacLight LIVE/DEAD viability kit reagents, SYTO 9 and propidium iodide (Molecular Probes), as described elsewhere (Webb et al., 2003), and examined with a confocal laser scanning microscope (Olympus LSMGB-200). Replicate image stacks (red and green scans) were recorded at $2 \mu \mathrm{m}$ intervals through the biofilm at random positions in the flow cell. Captured images were subsequently merged to obtain three-dimensional images of live and dead cells within individual microcolonies.

Analysis of colonies from biofilm effluent. Spent culture medium $(\sim 1 \mathrm{ml})$ emerging from individual flow cells was 'aseptically' collected into sterile tubes. Serial dilutions $\left(10^{-2}-10^{-10}\right)$ of each effluent sample in $\mathrm{M} 9$ medium were spread plated onto $\mathrm{LB}_{10}$ agar and detached/dispersed biofilm cells quantified and examined for morphotypic colony variants. Plates were incubated at $37^{\circ} \mathrm{C}$ and colonies were observed daily for up to 3 days. Total c.f.u. per $\mathrm{ml}$ of each effluent was determined.

Bacteriophage assay. Effluent samples were also examined for the bacteriophage activity at chosen intervals using a top-layer agar method (Eisenstark, 1967). In brief, aliquots $(20 \mu \mathrm{l})$ were serially diluted $\left(10^{-2}-10^{-8}\right)$ in SM (phage) buffer $(180 \mu \mathrm{l})$ (Hitch et al., 2004). Phage titres (p.f.u. $\mathrm{ml}^{-1}$ ) were determined by testing a $10 \mu \mathrm{l}$ aliquot of each dilution on sectors of LB agar plates overlaid with $\sim 3 \mathrm{ml}$ of a top agar of $\mathrm{LB}_{10} 0.8 \%(\mathrm{w} / \mathrm{v})$ agar seeded with an overnight Pseudomonas strain PAO1 LB broth culture. Effluents of selected strains were also tested on agars seeded with CF strain 3A. Phage activity was recorded after overnight incubation of the plates at $37{ }^{\circ} \mathrm{C}$. Each effluent was assayed on duplicate dilutions.

\section{RESULTS}

\section{Development of CF strain biofilms: decreased adherence and strain-specific microcolony architecture}

The developmental sequence of five CF strain biofilms was followed daily by bright-field microscopic observations. As we have reported previously, the CF strains were significantly less adherent to glass than strain PAO1 and non-CF isolates of $P$. aeruginosa (O'May et al., 2006). Thus, after $2 \mathrm{~h}$ incubation on the flow-cell glass coverslips, only the Melbourne clonal strain, MC1A, showed comparable adherence to strain PAO1 (data not shown). Strain 32A, an auto-aggregating strain that settled in static broth culture, exhibited small clusters of adherent cells as well as individual attached bacteria. Twenty-four hours postinoculation, strain PAO1 had formed a layer of cells covering the entire surface. By contrast, the CF strains showed little (strain MC1A) or no change in surface coverage compared to the $2 \mathrm{~h}$ time point. After this initial $24 \mathrm{~h}$ lag, however, biofilm growth and microcolony development occurred for all strains. By day 5 postinoculation, each CF strain had its own distinctive and reproducible microcolony architecture. Microcolonies for individual strains varied in their frequency of occurrence, size and structural features as summarized in Table 1 and

Table 1. Flow-cell biofilm analyses (5-7 days post-inoculation)

Data were obtained from two or three experiments.

\begin{tabular}{|c|c|c|c|}
\hline Strain & Microcolony morphology & $\begin{array}{l}\text { Mature microcolony diameter } \\
\qquad(\mu \mathrm{m})^{\star}\end{array}$ & $\begin{array}{l}\text { No. of morphological } \\
\text { variants in biofilm effluent } \dagger\end{array}$ \\
\hline PAO1 & Flat biofilm $(\sim 11 \mu \mathrm{m}$ thick $)$ & Microcolonies not seen $\neq$ & 2 \\
\hline $3 \mathrm{~A}$ & $\begin{array}{l}\text { Concentric ring (wall and central cells) to 'doughnut' forms } \\
\text { with central hole }\end{array}$ & $117.7 \pm 49.1 \quad(n=22)$ & $3-5$ \\
\hline $18 \mathrm{~A}$ & Outer wall cells surrounding structured, cellular centre & $50.7 \pm 26.1(n=17)$ & $2-5$ \\
\hline $32 \mathrm{~A}$ & $\begin{array}{l}\text { Distinctive 'slime' layer surrounding microcolonies with wall } \\
\text { cells and structured, compact cellular centre }\end{array}$ & $69.6 \pm 35.7(n=14)$ & 2 \\
\hline $75 \mathrm{~A}$ & Flat, $14-17 \mu \mathrm{m}$ thick, occasional large microcolonies only & $62.0 \pm 13.1(n=3) \S$ & 2 \\
\hline $\mathrm{MC} 1 \mathrm{~A}$ & $\begin{array}{l}\text { Flat, } \sim 11 \mu \mathrm{m} \text { thick, numerous small microcolonies with } \\
\text { structured wall cells and cellular centre }\end{array}$ & $41.3 \pm 19.1(n=8)$ & 2 \\
\hline
\end{tabular}

${ }^{*}$ Values are the mean $\pm \mathrm{SD} ; n$, number of mature microcolonies from which measurements were taken (bright-field and confocal microscopy). $\dagger$ Colonies were examined after $48 \mathrm{~h}$ incubation at $37{ }^{\circ} \mathrm{C}$.

$\ddagger$ Where microcolonies have been observed for strain PAO1 under similar experimental conditions, their mean diameter was $75.6 \pm 4.7$ at 5 days (Webb et al. 2003; unpublished observations).

§This strain grew predominantly as a flat biofilm. 
illustrated in Fig. 1 (bright-field microscopy) and Fig. 2 (confocal microscopy). Some strains (strains 3A, 18A and 32A) formed isolated microcolonies, while for others (strains $75 \mathrm{~A}$ and MC1A) the microcolonies emerged over time from the mat of cells covering the glass surface, as described in published studies of strain PAO1 (Webb et al., 2003). Microcolony sizes for all strains varied with their stage of development. The ones shown (Fig. 2) and measured (Table 1) were those at the upper size limit and/or (for strain 3A) the ones in which central hollowing (described below) was evident (henceforth referred to as 'mature microcolonies'). The mean height $\pm \mathrm{SD}$ of such microcolonies for strains $3 \mathrm{~A}, 32 \mathrm{~A}$ and $75 \mathrm{~A}$ at days $6-7$ (determined by confocal analysis of a combined total of 14 microcolonies of these strains) was $34.5 \pm 9.7 \mu \mathrm{m}$. Microcolonies of strains 18A $(n=6)$ and MC1A $(n=5)$ were shorter and less variable, at $21.7 \pm 0.8 \mu \mathrm{m}$ and $13.0 \pm 1.41 \mu \mathrm{m}$, respectively. In the experiments reported here, strain PAO1 grew rapidly, covering the flow cell and forming flat biofilms. Microcolony formation as described in previously published studies was not observed.

Strain 3A formed the largest microcolonies of the CF strains studied here. This strain's characteristic 'doughnut' appearance (central hollowing) was observed at day 4 (Figs $1 \mathrm{a}$ and 2b). By days 5-6, highly active motile bacteria filled the central area (Fig. 3a, arrow). The size of the voids increased with further biofilm development and motile cells were seen breaking out from the outer microcolony structure (Fig. 3b, c, arrows). These observations mirror those of seeding dispersal described for strain PAO1 (Purevdorj-Gage et al., 2005). In contrast, strain 32A had a characteristic encapsulated appearance (large, acellular, amorphous layer surrounding the microcolony) and essentially maintained a dense cellular interior (wall and central cells) over the period of the experiment (Figs 1c, 2e and $3 \mathrm{~d}$ ). Central motile cells were, however, occasionally observed even in the larger microcolonies of this strain. Strain 18A formed numerous, compact microcolonies over the glass surface (Figs $1 \mathrm{~b}$ and $2 \mathrm{c}$ ). Generally, these were of smaller size than the microcolonies of strains $3 \mathrm{~A}$ and $32 \mathrm{~A}$. Strain $75 \mathrm{~A}$ grew as a multilayered, flat biofilm by day 4 from which occasional tall $(62.0 \pm 13.1 \mu \mathrm{m})$ microcolonies emerged from day 5 (Fig. 2a, d). Strain MC1A also initially grew as a flat biofilm that subsequently formed numerous small microcolonies from day 5 onwards (Figs 1d and 2f). Central voids were not apparent by bright-field microscopy for strains 18A, 75A and MC1A at day 5 (e.g. Fig. 1b, d).

\section{Cell death and seeding dispersal occurs in CF strains}

Viability staining (BacLight LIVE/DEAD kit, Molecular Probes) and confocal analysis (day 7 post-inoculation)
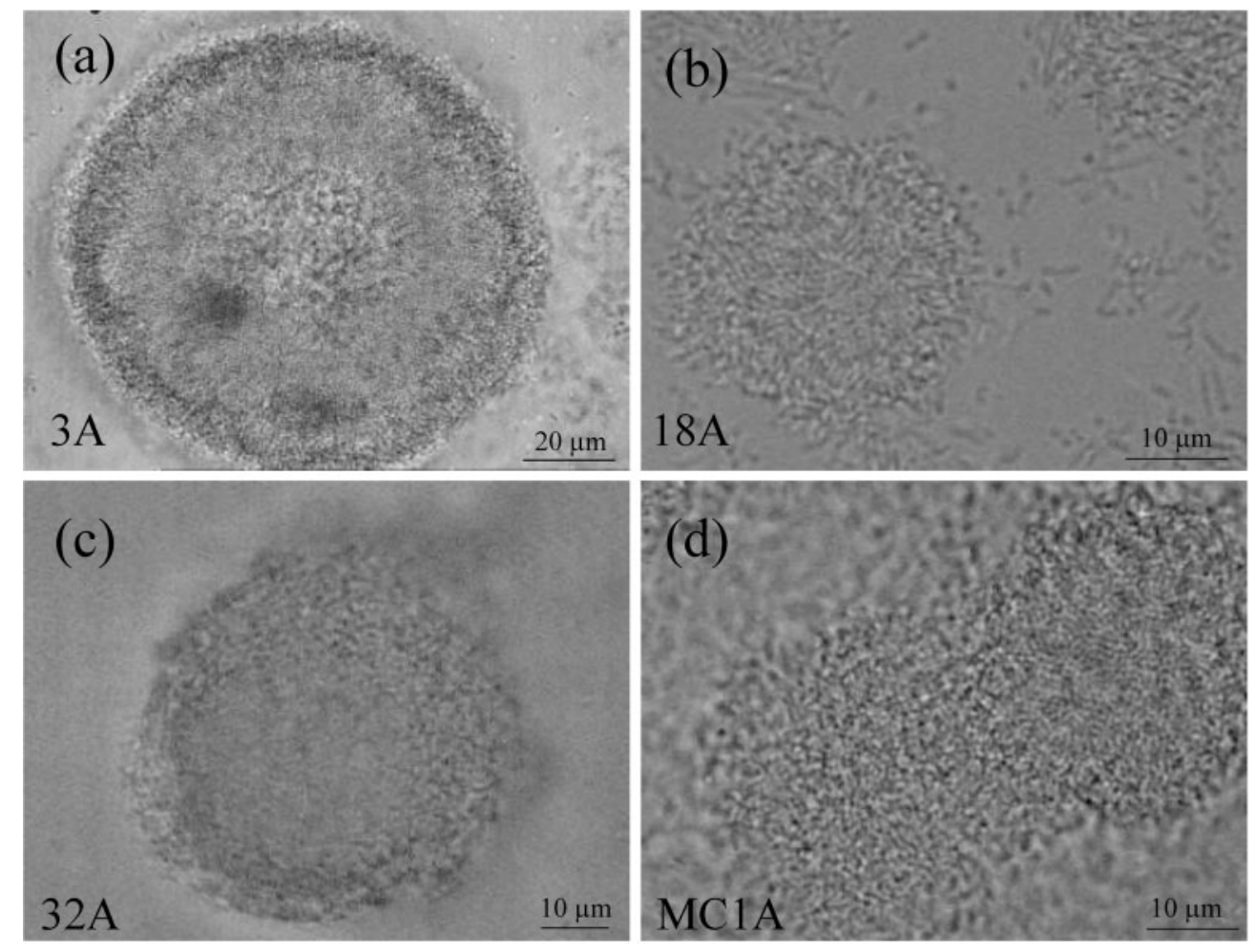

Fig. 1. Representative microcolonies of CF P. aeruginosa strains (a) $3 A$, (b) $18 A$, (c) $32 A$ and (d) MC1A cultivated in the flowcell system at 5 days post-inoculation (bright-field microscopy). Each strain shown had its own distinctive and reproducible microcolony architecture (Table 1). 

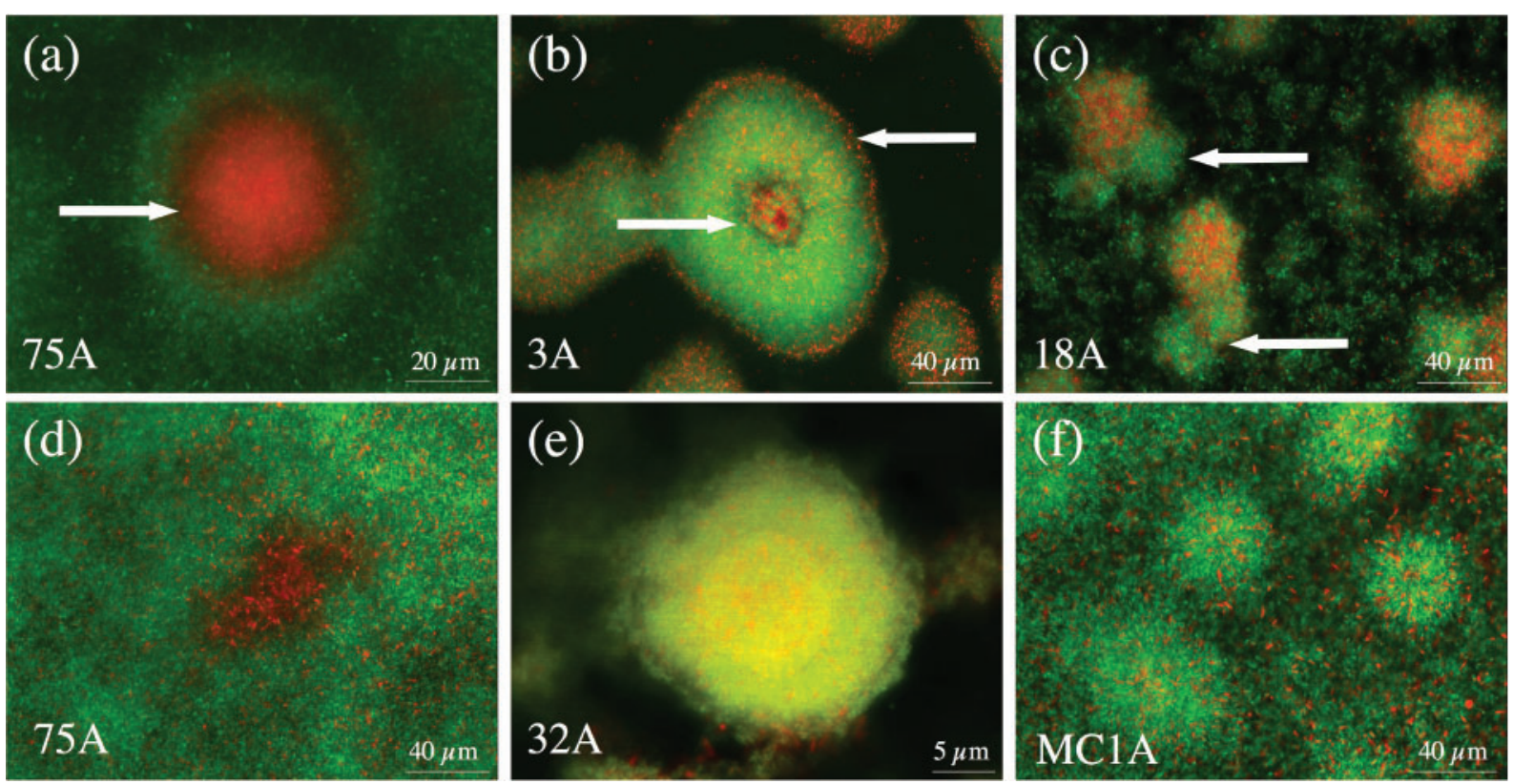

Fig. 2. Confocal photomicrographs of CF $P$. aeruginosa strain microcolonies and biofilm formation following viability staining (BacLight LIVE/DEAD kit, Molecular Probes) at 7 days post-inoculation. Strains shown are: (a) 75A (microcolony), (b) 3A, (c) $18 \mathrm{~A}$, (d) $75 \mathrm{~A}$ (flat biofilm), (e) 32A and (f) MC1A. Images are $x-y$ plane views through the microcolonies approximately onethird from the base. Green fluorescent cells are viable whereas red fluorescent cells are dead. Arrows indicate central cell death in a microcolony of strain $75 \mathrm{~A}$, central and peripheral cell death and hollowing in a microcolony of strain $3 \mathrm{~A}$, and seeding dispersal associated with central cell death in microcolonies of strain $18 \mathrm{~A}$.

revealed cell death in the maturing biofilms and microcolonies of all strains and evidence of seeding dispersal development (Fig. 2). The spatial organization and degree of bacterial death and lysis varied between strains but was always most marked at the base of the biofilm or microcolony and least apparent at the top of the microcolony. For strain $75 \mathrm{~A}$, extensive killing was seen in the centres of its relatively rare microcolonies and appeared identical to that reported for strain PAO1 microcolonies (Fig. 2a, arrow) (Webb et al., 2003). Large patches of cell death (greatest at base) were also observed even in the flat, undifferentiated portions of the biofilm for this strain (Fig. 2d). A similar pattern of lysis was observed in the flat PAO1 biofilms seen in these experiments (not shown). For strains 18A and MC1A, central cell death was also observed within microcolonies. At 7 days this death was more pronounced in strain $18 \mathrm{~A}$ than in strain MC1A, but central voids were occasionally seen in the larger microcolonies of both strains. Seeding dispersal in strain 18A is evident in Fig. 2(c) (arrows). Strain 3A showed cell death not only from the mature microcolony base upward but also from the microcolony edges inwards as well as central cell death and hollowing (Figs $2 b$ and $3 c$, arrows). A subpopulation of viable cells was also seen in the central hollow space of the microcolony. Seeding dispersal in association with the cell death and central hollowing was frequently observed for this strain (Fig. 3b, c, arrows). In contrast, the degree of cell death in strain 32A microcolonies was less than that seen in all of the above strains and, although centralized cell death was observed, hollowing and seeding dispersal were rarely observed for this strain in the 8 day experimental period (Fig. 3d).

\section{Phage titre in the effluent of mature CF strain biofilms}

Biofilm effluents were examined for viable bacteria (c.f.u.) and bacteriophage (p.f.u.) at days 4, 5, 6 and 7 postinoculation (one to three experiments). Phage titres were quantified by titration of effluents using a top-layer agar method (usually with strain PAO1 as target). Effluents of strains $3 \mathrm{~A}, 18 \mathrm{~A}$ and $32 \mathrm{~A}$, also examined on $\mathrm{CF}$ strain $3 \mathrm{~A}$ as target, yielded essentially identical phage titres to those obtained on strain PAO1. Between days 4 and 7 phage titres were detected in the effluents from all CF strains as for strain PAO1. For strain PAO1, they exceeded $10^{9}$ p.f.u. $\mathrm{ml}^{-1}$ throughout (days $4-7$ ). Phage titres of the CF strains were $>10^{6}$ p.f.u. $\mathrm{ml}^{-1}$ at days 4 and 5 postinoculation and reached levels $>10^{9}$ at day 7 , with the exception of strain 32A. For this latter strain, titres were more variable, but they were reproducibly $2-5 \operatorname{logs}$ lower (e.g. $<10^{5}$ p.f.u.) on day 7.

\section{Variant morphotypes in biofilm dispersal effluents}

Effluents from strain PAO1 and all CF strain biofilms contained $>10^{7}$ c.f.u. $\mathrm{ml}^{-1}$ (days $5-7$ post-inoculation). In 

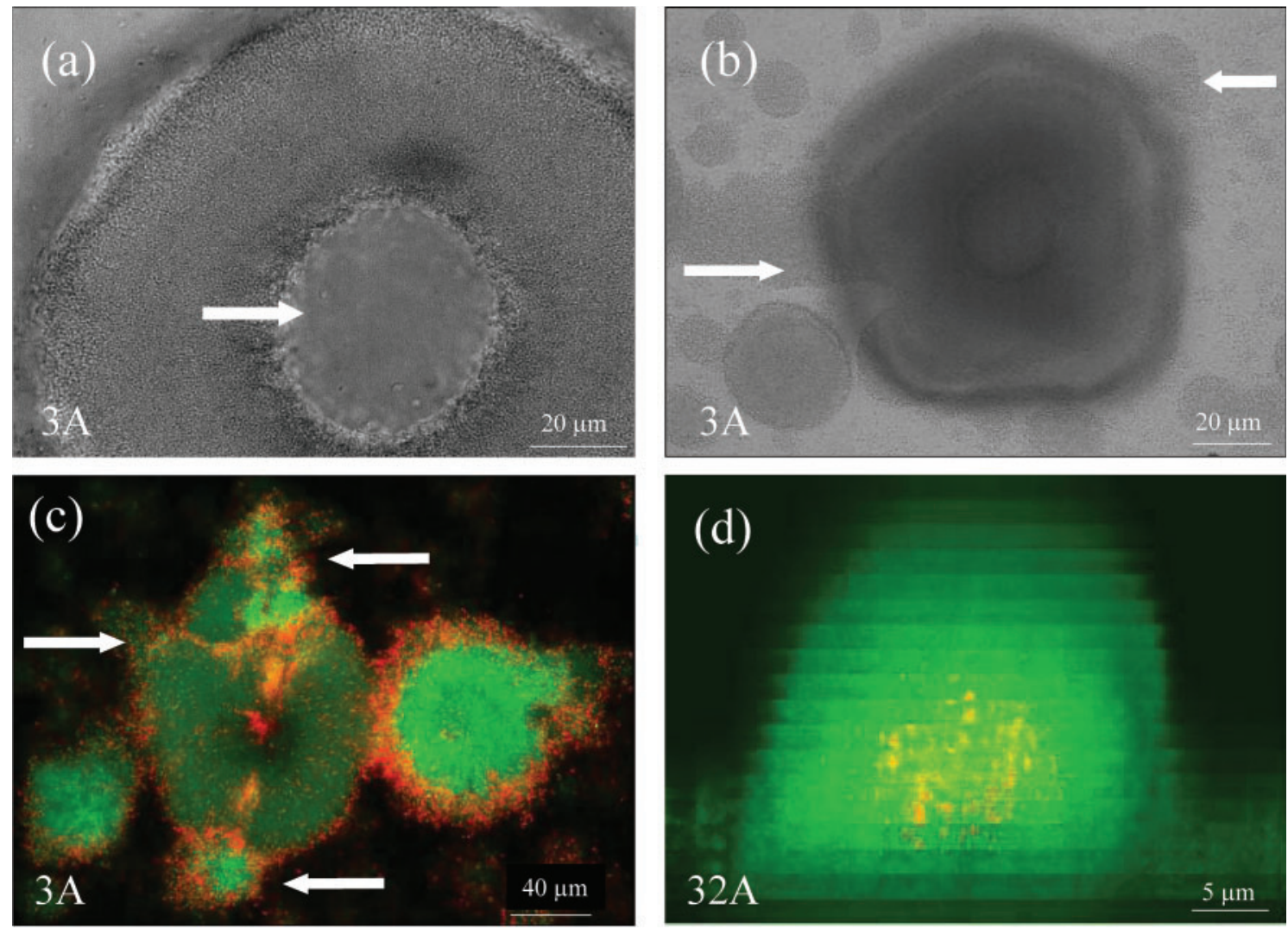

Fig. 3. Comparison of cell death and dispersal for representative 'mature' microcolonies of strains $3 A$ and $32 A$ at 7 days postinoculation. Strain 3A (seeding dispersal 'positive'): (a) mature microcolonies showing the highly motile central cellular interior (arrow), central hollowing and the formation of 'doughnut' microcolonies, (b) seeding dispersal (arrows) from mature microcolonies (bright-field microscopy), and (c) seeding dispersal (arrows) (viability staining and confocal microscopy, $x-y$ plane view, approximately one-third from the base of the microcolony). Strain 32A (seeding dispersal 'negative'): (d) no evident hollowing or seeding dispersal from the microcolony despite some central cell death (viability staining and confocal microscopy, $x-z$ plane composite, $2 \mu \mathrm{m}$ sections).

contrast to the homogeneous colony morphologies of each of the inoculum strains, at least two colony morphotypes were grown from the biofilm effluents of all strains (Fig. 4). For $P$. aeruginosa strain $\mathrm{PAO} 1$ these were large $(>4 \mathrm{~mm}$ diameter) colonies, sometimes with an irregular edge, like the inoculum strain, and small-colony ( $2 \mathrm{~mm}$ diameter variants (SCVs), as previously reported (Webb et al., 2004). The CF strains also showed these two morphotypes in the biofilm effluents. However, the situation was the reverse of that seen with strain PAO1. Despite all strains being mucoid on initial isolation, only strains $3 \mathrm{~A}$ and $18 \mathrm{~A}$ retained their mucoidy on subculture, and the other $\mathrm{CF}$ biofilm inoculum strains (strains 32A, 75A and MC1A) grew predominantly as small colonies with a translucent edges and yellow centres (Fig. 4b, c, d, e, f, insets). These latter CF inoculum strains gave rise to differing proportions of large-colony variants (LCVs), as well as SCVs. LCVs dominated the effluents of strains 75A and MC1A, but were less common in the effluents from strain $32 \mathrm{~A}$ (Fig. 4d, e, f). Strains $3 \mathrm{~A}$ and $18 \mathrm{~A}$ showed a greater heterogeneity of morphotypic variants, with up to five morphotypes isolated (Table 1; Fig. 4b, c). These strains were also the ones where significant seeding dispersal had been observed, as described above. On subculture on $\mathrm{LB}_{10}$ agar, these biofilm-generated variants were stable and did not revert to the parental morphotypes or convert into other morphotypes over at least two passages (data not shown).

\section{Seeding dispersal and QS signals}

CF strains 3A and 18A, which consistently showed seeding dispersal and had the greatest range of morphotypic variants, produced AHLs [3-oxo- $\mathrm{C}_{12}$-homoserine lactone (3-oxo- $\mathrm{C}_{12}$-HSL) and $\mathrm{C}_{4}$-homoserine lactone $\left(\mathrm{C}_{4}\right.$ - $\left.\mathrm{HSL}\right)$ ], and HAQs [Pseudomonas quinolone signal (PQS) and its biosynthetic precursor 4-hydroxy-2-heptylquiniline (HHQ)] signalling molecules. Strains 32A, 75A and $\mathrm{MC1A}$, which showed less cell death and morphotypic variation, did not produce 3 -oxo- $\mathrm{C}_{12}$-HSL. Strain MC1A 

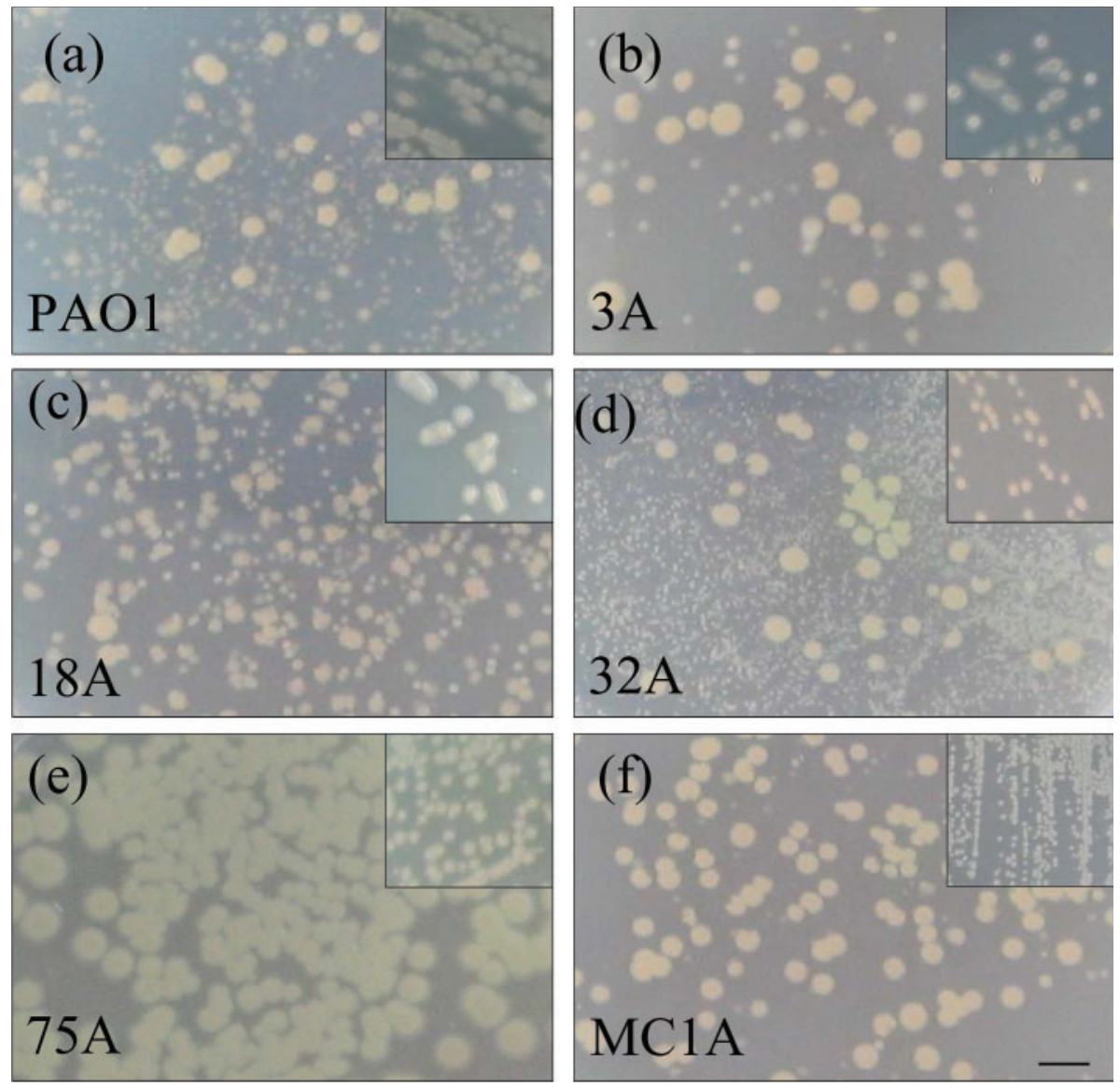

Fig. 4. Morphotypic colony variants seen in the flow-cell biofilm effluents at days $5-7$ post-inoculation (Table 1). (a) $P$. aeruginosa strain PAO1, (b-f) CF inoculum strains 3A, 18A, 32A, 75A and MC1A, respectively. Insets show the essentially uniform morphologies of the initial corresponding wild-type inoculum strains. (The wild-type CF strains $3 A$ and $18 \mathrm{~A}$ retained mucoidy while strains $32 \mathrm{~A}, 75 \mathrm{~A}$ and $\mathrm{MC} 1 \mathrm{~A}$, mucoid on initial isolation, grew as small colonies with a translucent edge and yellow centre.) Bar, $\sim 5 \mathrm{~mm}$.

was in addition $\mathrm{C}_{4}$-HSL negative, while strain $32 \mathrm{~A}$, which showed the lowest phage titres and least cell death, was also negative for PQS. Virulence factor production also correlated with this signalling pattern. Thus strains $3 \mathrm{~A}$ and $18 \mathrm{~A}$ remained mucoid, produced pyocyanin and were weakly positive for LasA and LasB activities, whereas the other three strains had lost these virulence capacities.

\section{DISCUSSION}

\section{CF strain biofilm development parallels that of strain PAO1}

There is little published information about the biofilm biology of clinical $P$. aeruginosa strains and how it compares to that of the more commonly studied laboratory model strain PAO1. In this study, isolates from chronically infected CF individuals were grown in a continuousculture flow-cell model under conditions (e.g. M9 minimal medium, standardized inocula) used to investigate seeding dispersal in strain PAO1 (Webb et al., 2003, 2004). The flow-cell system allowed for the slower developmental sequence of CF strain biofilms to be followed (8 day experimental period). It was found that the clinical isolates, despite their differences in adhesion and biofilm growth kinetics, and quite distinct microcolony morphologies, exhibited biofilm differentiation events analogous to those described for strain PAO1 (Webb et al., 2003). In particular, it was established that CF strains showed seeding dispersal as the biofilms matured. This active dispersal mechanism, not previously described in clinical strains, also showed a temporal association with the production of lytic bacteriophage and the generation of morphotypic variant dispersal cells as described for strain PAO1. The reproducibility of the differences seen with the CF strains suggests that each of these strains becomes locked into its own pattern of development. Overall, the results confirm that insights gained from studies of strain PAO1 biofilm differentiation and dispersal have clinical 
relevance. A noteworthy difference, however, was that morphotypic variants recovered from those $\mathrm{CF}$ strain biofilms showing marked seeding dispersal were much more heterogeneous than the variants recovered from strain PAO1.

\section{Role of microcolony size, phage induction and cell signalling in seeding dispersal}

The observation that seeding dispersal was most commonly seen in CF strains that produced large microcolonies (e.g. strain 3A, with mature microcolony diameters of $>100 \mu \mathrm{m})$ is consistent with that of Purevdorj-Gage et al. (2005), who reported that a microcolony diameter of $\sim 80 \mu \mathrm{m}$ was required for seeding dispersal in strain PAO1. Microcolonies of the other CF strains studied in this investigation rarely reached this size. In those microcolonies that did reach this size, central motile cells and seeding dispersal were observed. Cell death was, however, seen in the biofilms/microcolonies of all strains as they matured. Although strain PAO1 grew as a flat biofilm in this series of experiments, cell death associated with phage activity and dispersal variant production were nevertheless observed (in patches in the biofilm not in discrete microcolonies). Interestingly, CF strain $75 \mathrm{~A}$ also formed very flat biofilms similar to strain PAO1, although they were slower to develop. It also rarely formed microcolonies in these experiments. However, the microcolonies that were occasionally seen with this strain had an identical appearance and pattern of central cell death to those previously reported for strain PAO1 (Webb et al., 2003). Biofilm structural maturation has been shown to be dependent on environmental conditions (Klausen et al., 2003; Shrout et al., 2006). Hence, even minor (uncontrolled) differences in conditions could alter the pattern of biofilm development, resulting in flat biofilms especially for the faster-growing, motile strain PAO1, as is not uncommonly observed (Hentzer et al., 2001; Heydorn et al., 2002).

All CF strains showed bacteriophage activity and the phage titres reflected the occurrence of cell death within the biofilms. For instance, strain 32A, with the least death in microcolonies, had significantly lower phage titres than the other strains. To our knowledge, phage production has not previously been documented in relation to CF strain biofilm dispersal, as here. It is, however, now well established that Pf-like filamentous prophages are common among diverse $P$. aeruginosa clinical isolates. Pf1-like prophage sequences (detected by PCR with phage-specific primers) were present in 8 of 11 CF isolates obtained from different laboratories worldwide (Webb et al., 2003). Additionally, another recent study found that $P$. aeruginosa isolates from urinary tract catheters and from CF sputa contained Pf1-like phage sequences in their genomic DNA (Mooij et al., 2007). The fact that phage activity from all CF strains was detected on strain PAO1 suggests that these filamentous phages have a broad host specificity in $P$. aeruginosa. This is supported by the fact that titres of three CF strains tested on CF strain 3A were identical to the titres obtained on strain PAO1. It is also possible that isolates may contain multiple phages, any one of which could cause plaquing of strain PAO1 (Tan et al., 2007).

Purevdorj-Gage et al. (2005) found that las/rhl-mediated QS was required for seeding dispersal to occur in $P$. aeruginosa $\mathrm{PAO} 1$ and our results also support the conclusion that these processes are linked. The loss of QS signal production is a feature of isolates from chronic infections (Hentzer et al., 2005). It has recently been reported that genetic adaptation in the CF lung over time commonly results in mutations in the lasR gene, the elimination of which results in the loss of many acute virulence determinants (Nguyen \& Singh, 2006; Smith et al., 2006). Consistent with these reports, several of the clinical strains (strains 32A, 75A and MC1A) studied here were unable to produce one or more of the QS signal molecules and showed loss of acute virulence determinants. QSnegative (lasR) mutants of $P$. aeruginosa $\mathrm{PAO} 1$ are also reportedly significantly more resistant to cell lysis and death than the wild-type (Heurlier et al., 2005). Thus, the loss of AHL signals could possibly affect the degree of cell death and the evacuation of cells through the microcolony wall for these strains. While there did not appear to be a correlation between QS and phage production, strain 32A, which had the lowest phage titres, was also negative for PQS. Interestingly, PQS has been linked to $P$. aeruginosa autolysis (phage activity) (D'Argenio et al., 2002). Inactivation of lasR results in the accumulation of the PQS precursor, HHQ (Deziel et al., 2004). Thus, a LasRregulated balance of HAQs may limit $P$. aeruginosa autolysis (D’Argenio et al., 2007).

\section{Clinical strain dispersal variants show greater diversity than those of strain PAO1}

Biofilm growth has been shown to lead to the emergence of colony morphotypic variants in a variety of species (Kirisits et al., 2005; Koh et al., 2007; Mai-Prochnow et al., 2006; Webb et al., 2004). SCVs produced by strain PAO1 have significant functional differences from the wild-type strain (e.g. enhanced attachment, accelerated biofilm development) (Kirisits et al., 2005; Webb et al., 2004). Further studies are needed to investigate the functional significance of CF strain variants and the exact mechanism(s) by which they are generated. In particular, it will be of interest to determine whether there are CF strain variants that are better adapted to colonization and/or survival (e.g. by contributing to antibiotic resistance) under conditions found in the CF airway. The in vitro observations to date are consistent with the high degree of phenotypic variation widely reported in $P$. aeruginosa isolates from CF sputa despite the fact that most individuals are colonized with one (or relatively few) genotypic clone(s) of the organism (Foweraker et al., 2005; VanDevanter \& Van Dalfsen, 2005). It seems likely that in vivo the generation of biofilm 
dispersal variants represents a key adaptive response that enables protection against antibiotics and host defences, favours recolonization in new niches and ensures continued biofilm growth in pulmonary infection. This study identified variants by colony morphology but morphologically identical clones may show functional variation (Mai-Prochnow et al., 2006). Indeed, we have preliminary evidence from studies of substrate utilization profiles (Biolog Microplates) that this is the case for the dispersal cells of some CF strains.

There are a variety of mechanisms by which variant production may be facilitated in maturing biofilms. Reversible phenotypic and functional variation (e.g. phase variation and persister cells) has been reported in $P$. aeruginosa (Deziel et al., 2001; Drenkard \& Ausubel, 2002; Lewis, 2005) and phase variation observed for some of the CF strains examined in this study (unpublished observations). Thus, LCVs of strain 32A were motile and expressed virulence factors (LasA, LasB and pyocyanin, as well as QS signal molecules) while SCVs of strain $32 \mathrm{~A}$ and the $32 \mathrm{~A}$ inoculum strain were non-motile and did not express these virulence factors. Such phenotypic switching could also be observed after serial passage and other culture manipulations of this and other strains from this study (unpublished data).

Biofilm growth also facilitates heritable diversification through genetic exchange and mutagenesis. Two recognized mechanisms that accelerate the latter are the stressinducible genes, usually part of the SOS regulon, that generate genetic variability in times of stress such as occurs in ageing biofilms and regulator genes (e.g. $m u t S$ of the bacterial DNA mismatch repair system), whose functional loss increases the rate of genetic variability and gives rise to 'hypermutable/mutator' strains (Barraud et al., 2006; Moyano et al., 2007; Sanders et al., 2006; Smania et al., 2004). Adaptations will be selected for and may be linked to hypermutator mutations if they confer a selective advantage (Hall \& Henderson-Begg, 2006; Montanari et al., 2007). The association between multidrug antimicrobial resistance and hypermutability in chronic CF infection has been well documented (Maciá et al., 2004, 2005; Oliver et al., 2000, 2004). Other common genes targeted in chronic infection include the las $R$ and mexZ genes (Smith et al., 2006). Loss of lasR confers a growth advantage with particular carbon and nitrogen sources as well as increased $\beta$-lactamase activity and resistance to ceftazidime, a widely used $\beta$-lactam antibiotic in $\mathrm{CF}$ (D'Argenio et al., 2007). Loss of mexZ upregulates the multidrug-efflux pump, MexXY-OprM, that is associated with resistance to the aminoglycoside tobramycin, also commonly used in CF treatment (D'Argenio et al., 2007). While selection of mutS mutations with adaptive responses such as those above may be one mechanism by which $\mathrm{CF}$ strains give rise to the greater diversity of biofilm dispersal progeny compared to strain PAO1, there are likely other as-yet-unrecognized genes that are also important in causing hypermutability. A recent study found that the level of mutS mutators in multidrug-resistant epidemic strains (strains likely to be particularly well adapted to CF airway survival) was low (13\%, 2/15) (Kenna et al., 2007).

In summary, this paper reports new insights into how biofilm differentiation and dispersal might contribute to the generation of diversity in CF P. aeruginosa isolates and the persistence and intractable nature of airway infections with this organism. These insights have significant implications for ongoing research and the development of improved treatment strategies for chronic Pseudomonas infections in CF. Early and aggressive therapy to prevent and delay colonization, conversion to mucoidy and biofilm growth, and the selection of mutator strains is clearly desirable, as others have concluded (Kenna et al., 2007). This study, however, suggests that successful treatment is only likely to be accomplished if disease management also includes the targeting of the dominant dispersal variants and/or the mechanisms by which they are generated. Further research into these areas is thus clearly warranted.

\section{ACKNOWLEDGEMENTS}

This work was supported by grants from the University of Tasmania Institutional Research Grants Scheme, the Australian National Health and Medical Research Council, and the Australian Research Council. We thank Mr Paul Halasz, Histology and Microscopy Unit, School of Medical Sciences, University of New South Wales, for his assistance with the confocal microscopic analyses; Mr Nicolas Barraud for guidance with the flow-cell assays; Dr Richard Alm for supplying strain PAO1; Dr David Armstrong and Ms Rosemary Carzino for supplying strain MC1A; Mr Richard Bradbury for the genetic analyses of the CF strains; and Professor Paul Williams, Centre for Biomolecular Sciences, University of Nottingham, UK, and members of his research group, particularly Dr Stephen Diggle, for their contributions to the Pseudomonas signalling and virulence assays.

\section{REFERENCES}

Armstrong, D. S., Nixon, G. M., Carzino, R., Bigham, A., Carlin, J. B., Robins-Browne, R. M. \& Grimwood, K. (2002). Detection of a widespread clone of Pseudomonas aeruginosa in a pediatric cystic fibrosis clinic. Am J Respir Crit Care Med 166, 983-987.

Barraud, N., Hassett, D. J., Hwang, S. H., Rice, S. A., Kjelleberg, S. \& Webb, J. S. (2006). Involvement of nitric oxide in biofilm dispersal of Pseudomonas aeruginosa. J Bacteriol 188, 7344-7353.

Boles, B. R., Thoendel, M. \& Singh, P. K. (2004). Self-generated diversity produces "insurance effects" in biofilm communities. Proc Natl Acad Sci U S A 101, 16630-16635.

Burns, J. L., Gibson, R. L., McNamara, S., Yim, D., Emerson, J., Rosenfeld, M., Hiatt, P., McCoy, K., Castile, R. \& other authors (2001). Longitudinal assessment of Pseudomonas aeruginosa in young children with cystic fibrosis. J Infect Dis 183, 444-452.

Costerton, J. W., Stewart, P. S. \& Greenberg, E. P. (1999). Bacterial biofilms: a common cause of persistent infections. Science 284, 1318-1322.

D’Argenio, D. A., Calfee, M. W., Rainey, P. B. \& Pesci, E. C. (2002). Autolysis and autoaggregation in Pseudomonas aeruginosa colony morphology mutants. J Bacteriol 184, 6481-6489.

D’Argenio, D. A., Wu, M., Hoffman, L. R., Kulasekara, H. D., Déziel, E., Smith, E. E., Nguyen, H., Ernst, R. K., Larson Freeman, T. J. \& other 
authors (2007). Growth phenotypes of Pseudomonas aeruginosa lasR mutants adapted to the airways of cystic fibrosis patients. Mol Microbiol 64, 512-533.

Deziel, E., Comeau, Y. \& Villemur, R. (2001). Initiation of biofilm formation by Pseudomonas aeruginosa 57RP correlates with emergence of hyperpiliated and highly adherent phenotypic variants deficient in swimming, swarming, and twitching motilities. J Bacteriol 183, 1195-1204.

Deziel, E., Lepine, F., Milot, S., He, J., Mindrinos, M. N., Tompkins, R. G. \& Rahme, L. G. (2004). Analysis of Pseudomonas aeruginosa 4hydroxy-2-alkylquinolines (HAQs) reveals a role for 4-hydroxy-2heptylquinoline in cell-to-cell communication. Proc Natl Acad Sci U S A 101, 1339-1344.

Diggle, S. P., Winzer, K., Lazdunski, A., Williams, P. \& Cámara, M. (2002). Advancing the quorum in Pseudomonas aeruginosa: MvaT and the regulation of $\mathrm{N}$-acylhomoserine lactone production and virulence gene expression. J Bacteriol 184, 2576-2586.

Diggle, S. P., Winzer, K., Chhabra, S. R., Worrall, K. E., Cámara, M. \& Williams, P. (2003). The Pseudomonas aeruginosa quinolone signal molecule overcomes the cell density-dependency of the quorum sensing hierarchy, regulates rhl-dependent genes at the onset of stationary phase and can be produced in the absence of LasR. Mol Microbiol 50, 29-43.

Drenkard, E. \& Ausubel, F. M. (2002). Pseudomonas biofilm formation and antibiotic resistance are linked to phenotypic variation. Nature 416, 740-743.

Eisenstark, A. (1967). Bacteriophage techniques. In Methods in Virology, vol. 1, pp. 449-524. Edited by K. Maramorosch \& H. Koprowski. New York: Academic Press.

Foweraker, J. E., Laughton, C. R., Brown, D. F. \& Bilton, D. (2005). Phenotypic variability of Pseudomonas aeruginosa in sputa from patients with acute infective exacerbation of cystic fibrosis and its impact on the validity of antimicrobial susceptibility testing. J Antimicrob Chemother 55, 921-927.

Hall, L. M. \& Henderson-Begg, S. K. (2006). Hypermutable bacteria isolated from humans - a critical analysis. Microbiology 152, 2505-2514.

Hassett, D. J., Cuppoletti, J., Trapnell, B., Lymar, S. V., Rowe, J. J., Yoon, S. S., Hilliard, G. M., Parvatiyar, K., Kamani, M. C. \& other authors (2002). Anaerobic metabolism and quorum sensing by Pseudomonas aeruginosa biofilms in chronically infected cystic fibrosis airways: rethinking antibiotic treatment strategies and drug targets. Adv Drug Deliv Rev 54, 1425-1443.

Head, N. E. \& Yu, H. (2004). Cross-sectional analysis of clinical and environmental isolates of Pseudomonas aeruginosa: biofilm formation, virulence, and genome diversity. Infect Immun 72, 133-144.

Hentzer, M., Teitzel, G. M., Balzer, G. J., Heydorn, A., Molin, S., Givskov, M. \& Parsek, M. R. (2001). Alginate overproduction affects Pseudomonas aeruginosa biofilm structure and function. J Bacteriol 183, 5395-5401.

Hentzer, M., Eberl, L. \& Givskov, M. (2005). Transcriptome analysis of Pseudomonas aeruginosa biofilm development: anaerobic respiration and iron limitation. Biofilms 2, 37-61.

Heurlier, K., Denervaud, V., Haenni, M., Guy, L., Krishnapillai, V. \& Haas, D. (2005). Quorum-sensing-negative (lasR) mutants of Pseudomonas aeruginosa avoid cell lysis and death. J Bacteriol 187, 4875-4883.

Heydorn, A., Ersboll, B., Kato, J., Hentzer, M., Parsek, M. R., TolkerNielsen, T., Givskov, M. \& Molin, S. (2002). Statistical analysis of Pseudomonas aeruginosa biofilm development: impact of mutations in genes involved in twitching motility, cell-to-cell signaling, and stationary-phase sigma factor expression. Appl Environ Microbiol 68, 2008-2017.
Hitch, G., Pratten, J. \& Taylor, P. W. (2004). Isolation of bacteriophages from the oral cavity. Lett Appl Microbiol 39, 215-219.

Holloway, B. W. (1955). Genetic recombination in Pseudomonas aeruginosa. J Gen Microbiol 13, 572-581.

Kenna, D. T., Doherty, C. J., Foweraker, J., Macaskill, L., Barcus, V. A. \& Govan, J. R. W. (2007). Hypermutability in environmental Pseudomonas aeruginosa and in populations causing pulmonary infection in individuals with cystic fibrosis. Microbiology 153, 1852-1859.

Kirisits, M. J., Prost, L., Starkey, M. \& Parsek, M. R. (2005). Characterization of colony morphology variants isolated from $P s e u$ domonas aeruginosa biofilms. Appl Environ Microbiol 71, 4809-4821.

Kirov, S. M., Webb, J. S. \& Kjelleberg, S. (2005). Clinical significance of seeding dispersal in biofilms. Microbiology 151, 3452-3453.

Klausen, M., Heydorn, A., Ragas, P., Lambertsen, L., AaesJorgensen, A., Molin, S. \& Tolker-Nielsen, T. (2003). Biofilm formation by Pseudomonas aeruginosa wild type, flagella and type IV pili mutants. Mol Microbiol 48, 1511-1524.

Koh, K. S., Lam, K. W., Alhede, M., Queck, S. Y., Labbate, M., Kjelleberg, S. \& Rice, S. A. (2007). Phenotypic diversification and adaptation of Serratia marcescens MG1 biofilm-derived morphotypes. J Bacteriol 189, 119-130.

Lee, B., Haagensen, J. A., Ciofu, O., Andersen, J. B., Hoiby, N. \& Molin, S. (2005). Heterogeneity of biofilms formed by nonmucoid Pseudomonas aeruginosa isolates from patients with cystic fibrosis. J Clin Microbiol 43, 5247-5255.

Lewis, K. (2005). Persister cells and the riddle of biofilm survival. Biochemistry (Mosc) 70, 267-274.

Lyczak, J. B., Cannon, C. L. \& Pier, G. B. (2002). Lung infections associated with cystic fibrosis. Clin Microbiol Rev 15, 194-222.

Maciá, M. D., Borrell, N., Perez, J. L. \& Oliver, A. (2004). Detection and susceptibility testing of hypermutable Pseudomonas aeruginosa strains with the Etest and disk diffusion. Antimicrob Agents Chemother 48, 2665-2672.

Maciá, M. D., Blanquer, D., Togores, B., Sauleda, J., Perez, J. L. \& Oliver, A. (2005). Hypermutation is a key factor in development of multiple-antimicrobial resistance in Pseudomonas aeruginosa strains causing chronic lung infections. Antimicrob Agents Chemother 49, 3382-3386.

Mahenthiralingam, E., Campbell, M. E. \& Speert, D. P. (1994). Nonmotility and phagocytic resistance of Pseudomonas aeruginosa isolates from chronically colonized patients with cystic fibrosis. Infect Immun 62, 596-605.

Mahenthiralingam, E., Campbell, M. E., Foster, J., Lam, J. S. \& Speert, D. P. (1996). Random amplified polymorphic DNA typing of Pseudomonas aeruginosa isolates recovered from patients with cystic fibrosis. J Clin Microbiol 34, 1129-1135.

Mai-Prochnow, A., Evans, F., Dalisay-Saludes, D., Stelzer, S., Egan, S., James, S., Webb, J. S. \& Kjelleberg, S. (2004). Biofilm development and cell death in the marine bacterium Pseudoalteromonas tunicata. Appl Environ Microbiol 70, 3232-3238.

Mai-Prochnow, A., Webb, J. S., Ferrari, B. C. \& Kjelleberg, S. (2006). Ecological advantages of autolysis during the development and dispersal of Pseudoalteromonas tunicata biofilms. Appl Environ Microbiol 72, 5414-5420.

Middleton, B., Rodgers, H. C., Camara, M., Knox, A. J., Williams, P. \& Hardman, A. (2002). Direct detection of $N$-acylhomoserine lactones in cystic fibrosis sputum. FEMS Microbiol Lett 207, 1-7.

Moller, S., Sternberg, C., Andersen, J. B., Christensen, B. B., Ramos, J. L., Givskov, M. \& Molin, S. (1998). In situ gene expression in mixedculture biofilms: evidence of metabolic interactions between community members. Appl Environ Microbiol 64, 721-732. 
Montanari, S., Oliver, A., Salerno, P., Mena, A., Bertoni, G., Tümmler, B., Cariani, L., Conese, M., Döring, G. \& other authors (2007). Biological cost of hypermutation in Pseudomonas aeruginosa strains from patients with cystic fibrosis. Microbiology 153, 1445-1454.

Mooij, M. J., Drenkard, E., Llamas, M. A., Vandenbroucke-Grauls, C. M., Savelkoul, P. H., Ausubel, F. M. \& Bitter, W. (2007). Characterization of the integrated filamentous phage Pf5 and its involvement in small-colony formation. Microbiology 153, 1790-1798.

Moyano, A. J., Luján, A. M., Argarana, C. E. \& Smania, A. M. (2007). MutS deficiency and activity of the error-prone DNA polymerase IV are crucial for determining mucA as the main target for mucoid conversion in Pseudomonas aeruginosa. Mol Microbiol 64, 547-559.

Nguyen, D. \& Singh, P. K. (2006). Evolving stealth: genetic adaptation of Pseudomonas aeruginosa during cystic fibrosis infections. Proc Natl Acad Sci U S A 103, 8305-8306.

O’May, C. Y., Reid, D. W. \& Kirov, S. M. (2006). Anaerobic culture conditions favor biofilm-like phenotypes in Pseudomonas aeruginosa isolates from patients with cystic fibrosis. FEMS Immunol Med Microbiol 48, 373-380.

Oliver, A., Canton, R., Campo, P., Baquero, F. \& Blazquez, J. (2000). High frequency of hypermutable Pseudomonas aeruginosa in cystic fibrosis lung infection. Science 288, 1251-1254.

Oliver, A., Levin, B. R., Juan, C., Baquero, F. \& Blázquez, J. (2004). Hypermutation and the preexistence of antibiotic-resistant Pseudomonas aeruginosa mutants: implications for susceptibility testing and treatment of chronic infections. Antimicrob Agents Chemother 48, 4226-4233.

Purevdorj-Gage, B., Costerton, W. J. \& Stoodley, P. (2005). Phenotypic differentiation and seeding dispersal in non-mucoid and mucoid Pseudomonas aeruginosa biofilms. Microbiology 151, 1569-1576.

Saiman, L. \& Siegel, J. (2004). Infection control in cystic fibrosis. Clin Microbiol Rev 17, 57-71.

Sanders, L. H., Rockel, A., Lu, H., Wozniak, D. J. \& Sutton, M. D. (2006). Role of Pseudomonas aeruginosa dinB-encoded DNA polymerase IV in mutagenesis. J Bacteriol 188, 8573-8585.

Shrout, J. D., Chopp, D. L., Just, C. L., Hentzer, M., Givskov, M. \& Parsek, M. R. (2006). The impact of quorum sensing and swarming motility on Pseudomonas aeruginosa biofilm formation is nutritionally conditional. Mol Microbiol 62, 1264-1277.
Smania, A. M., Segura, I., Pezza, R. J., Becerra, C., Albesa, I. \& Argarana, C. E. (2004). Emergence of phenotypic variants upon mismatch repair disruption in Pseudomonas aeruginosa. Microbiology 150, 1327-1338.

Smith, E. E., Buckley, D. G., Wu, Z., Saenphimmachak, C., Hoffman, L. R., D'Argenio, D. A., Miller, S. I., Ramsey, B. W., Speert, D. P. \& other authors (2006). Genetic adaptation by Pseudomonas aeruginosa to the airways of cystic fibrosis patients. Proc Natl Acad Sci U S A 103, 8487-8492.

Stewart, P. S. \& Costerton, J. W. (2001). Antibiotic resistance of bacteria in biofilms. Lancet 358, 135-138.

Stoodley, P., Sauer, K., Davies, D. G. \& Costerton, J. W. (2002). Biofilms as complex differentiated communities. Annu Rev Microbiol 56, 187-209.

Tan, C., Rice, S. A., Webb, J. S. \& Kjelleberg, S. (2007). The involvement of Pf4 filamentous phage in Pseudomonas aeruginosa biofilm development. In Biofilms 2007 (Proceedings of the 4th ASM Conference on Biofilms, 25-29 March 2007, Quebec, Canada), abstract A49, p. 65. Washington, DC: American Society for Microbiology.

VanDevanter, D. R. \& Van Dalfsen, J. M. (2005). How much do Pseudomonas biofilms contribute to symptoms of pulmonary exacerbation in cystic fibrosis? Pediatr Pulmonol 39, 504-506.

Webb, J. S., Thompson, L. S., James, S., Charlton, T., Tolker-Nielsen, T., Koch, B., Givskov, M. \& Kjelleberg, S. (2003). Cell death in Pseudomonas aeruginosa biofilm development. J Bacteriol 185, 4585-4592.

Webb, J. S., Lau, M. \& Kjelleberg, S. (2004). Bacteriophage and phenotypic variation in Pseudomonas aeruginosa biofilm development. J Bacteriol 186, 8066-8073.

Wilschanski, M., Zielenski, J., Markiewicz, D., Tsui, L. C., Corey, M., Levison, H. \& Durie, P. R. (1995). Correlation of sweat chloride concentration with classes of the cystic fibrosis transmembrane conductance regulator gene mutations. J Pediatr 127, 705-710.

Worlitzsch, D., Tarran, R., Ulrich, M., Schwab, U., Cekici, A., Meyer, K. C., Birrer, P., Bellon, G., Berger, J. \& other authors (2002). Effects of reduced mucus oxygen concentration in airway Pseudomonas infections of cystic fibrosis patients. J Clin Invest 109, 317-325.

Edited by: P. Cornelis 